\title{
Modelos científicos em tempos de pandemia
}

\author{
Scientific models in times of pandemic
}

\begin{abstract}
Alexander Maar*
Resumo: A pandemia de COVID-19 deu maior visibilidade ao trabalho de epidemiologistas, e em particular ao uso de modelos epidemiológicos. Projeções da expansão da doença, número de casos e o seu pico esperado, são amplamente divulgadas na mídia. Políticas de saúde pública, como medidas de isolamento social, são justificadas à população com base na necessidade de se 'achatar a curva', e evitar o colapso do sistema de saúde. Mas o público não é informado sobre os usos e limitações dos modelos. A necessidade de recalibrarmos os modelos com novos dados e de revisarmos projeções também são pouco compreendidas e por vezes se tornam fonte de frustração, alimentando ceticismo para com a verdade científica. Neste artigo eu discuto brevemente de que maneira a reflexão filosófica sobre os usos dos modelos, e de suas propriedades epistêmicas - cognição, explicação e entendimento - pode mitigar esses problemas.
\end{abstract}

Palavras-chave: Modelos científicos; Modelos epidemiológicos; COVID-19; Pandemia; Projeção; Ciência na mídia

Abstract: The COVID-19 pandemic has given greater visibility to the work of epidemiologists, and in particular to the use of epidemiological models. Projections of the disease's expansion, number of cases and its expected peak, are widely reported in the media. Public health policies, such as measures of social isolation, are justified to the population based on the need to 'flatten the curve', and to prevent the collapse of the health system. But the public is not informed about uses and limitations of models. The need to recalibrate models with new data and to revise projections are also poorly understood and sometimes become a source of frustration, fuelling scepticism towards scientific truth. In this article, I briefly discuss how philosophical reflection on the uses of models and their epistemic properties - cognition, explanation and understanding - can mitigate these problems.

Keywords: Scientific models; Epidemiological models; COVID-19; Pandemic; Projection; Science in the media

\section{Modelos científicos}

A atual pandemia do COVID-19 causada pelo coronavírus Sars-Cov-2, dentre suas inúmeras consequências amplamente negativas, trouxe ao menos uma potencialmente positiva. Trata-se da ampla divulgação na mídia da importância do uso de modelos científicos, no caso modelos de propagação epidemiológica do novo coronavírus, para orientar políticas públicas relativas à pandemia. Procura-se nos modelos um guia para a ação, uma justificativa para a adoção ou não de normas de restrição de circulação de pessoas ou quarentena compulsória. Deseja-se evitar por meio de tais medidas os cenários mais graves projetados por tais modelos, aqueles que teoricamente se seguiriam caso os governos decidissem não interferir na velocidade de propagação do vírus e em sua prevalência. É a crença no poder preditivo de modelos que fundamenta muitas das decisões de cunho sanitário. Essa crença é a responsável pela popularidade do jargão jornalístico o

Professor no departamento de Filosofia da Universidade Estadual de Londrina, Londrina, PR. E-mail: alexander.maar@web.de ORCID: https://orcid.org/oooo-0oo1-8336-7884 
'achatamento da curva', evocado como medida necessária para evitar o colapso dos sistemas de saúde.

No âmbito científico modelos desde há muito possuem protagonismo. Alguns de grande importância incluem: a dupla hélice do DNA (genética); o modelo do equilíbrio geral de preços (economia); o modelo do Big Bang (cosmologia); a sucessão de modelos atômicos, desde Dalton a Bohr e Schrödinger (físico-química); modelos evolutivos (biologia); modelos de circulação geral do clima (climatologia); modelos de comportamento social (sociologia); modelos epidemiológicos e muitos outros. Uma considerável parcela de tempo do trabalho dos cientistas é dedicada ao estudo e interpretação dos modelos e ao grau de confiabilidade de suas projeções. Em conseguinte, também filósofos da ciência passaram a dedicar-lhes atenção.

Na literatura especializada encontramos uma miríade de tipos de modelos: teóricos, matemáticos, escalares, heurísticos, fenomenológicos, físicos, computacionais, modelosteste, entre outros. Com frequência há um overlap entre essas classificações. Norman Frigg e Stephan Hartmann destacam, contudo, que do ponto de vista da filosofia é mais frutífero investigar de onde se origina essa profusão de termos ${ }^{1}$. Em geral, essas categorias surgem quando filósofos se dedicam a três perguntas fundamentais em relação a modelos: (1) De que maneira os modelos representam os fenômenos a que se referem? (semântica); (2) De que forma os modelos se prestam ao entendimento e/ou explicação desses fenômenos? (epistemologia). (3) O que são os diferentes tipos de modelos? (ontologia). A brevidade pretendida do presente texto permitirá a discussão introdutória de apenas uma pequena parte de (2).

\section{Modelos epidemiológicos}

O comportamento sistêmico de transmissão de uma doença infecciosa em uma determinada população pode ser representado por meio de modelos. Esses variam de básicos a altamente complexos, dependendo do número de variáveis relevantes, e da quantidade de dados disponíveis. Inicialmente, esses modelos são formulados como problemas de valor inicial para sistemas de equações diferenciais, e posteriormente são analisados matematicamente ${ }^{2}$. Assim, um sistema dinâmico (no caso, um sistema de contágio viral) evolui de acordo com regras matemáticas expressas por meio de equações diferenciais - é, portanto, determinístico. Há uma regra matemática que descreve, por exemplo, de que forma a prevalência da infecção em uma população deve evoluir ao longo do tempo.

Em outras palavras, dizemos que o estado do sistema $S$ em um tempo anterior $t_{1}$, junto com as regras relevantes, determina o estado de $S$ em $t_{2}$. A trajetória evolutiva é unicamente determinada pelas regras relevantes - não há bifurcações ou probabilidades. Mas se a descrição do estado de $S_{(\mathrm{t} 1)}$ e a quantificação dos parâmetros forem apenas aproximadas, o efeito projetado será impreciso: “a falta de dados confiáveis torna a estimativa de parâmetros precisos difícil, de modo que pode ser possível apenas estimar um intervalo de valores para alguns parâmetros"3.

Um sistema dinâmico, vale lembrar, não é um sistema físico, e sim um modelo de um sistema físico. Trata-se de um sistema que modela um sistema real de acordo com essas regras matemáticas, de modo que é mais preciso referirmo-nos a ele como modelo $M$ de $S$,

\footnotetext{
${ }^{1}$ FRIGG e HARTMANN, Models in Science.

${ }^{2}$ A incógnita de um problema de valor inicial é uma função que satisfaz a equação diferencial e a condição inicial.

${ }^{3}$ HETHCOTE, Three Basic Epidemiological Models, 121.
} 
ou $M_{\mathrm{s}}$. Essas regras que se aplicam a $M_{\mathrm{s}}$ são formuladas para "as regiões de estabilidade assintótica para os pontos de equilíbrio e retratos dos planos de fase para as soluções são apresentados" 4 . Diversos parâmetros são então estimados para que se possam projetar, por exemplo, os níveis necessários de vacinação a fim de conferir imunidade de rebanho à população. No caso da presente pandemia, uma das dificuldades em se projetar esses níveis necessários reside no fato de que para nenhum dos coronavírus conhecidos e capazes de infectar humanos existem vacinas. O parâmetro de comparação utilizado é por vezes o comportamento epidemiológico de outros patógenos, como o HiN1.

As projeções podem ater-se a observações iniciais de casos e abster-se de comparações. Saulo Bastos e Daniel Cajueiro, ao modelar a evolução inicial do COVID-19 no Brasil, dão ótimo exemplo disso ${ }^{5}$. A partir de dados de 25 de fevereiro a 28 de março de 2020 eles modelaram e projetaram a evolução da doença segundo duas variações do modelo SIR . Eles incluíram no modelo um parâmetro que explica o efeito esperado das medidas de isolamento social. Eles concluíram inicialmente que essas medidas têm eficácia teórica no achatamento do crescimento dos casos, e permitem determinar uma data para o relaxamento das mesmas. A conclusão mais saliente, contudo, é a de que o fim prematuro do isolamento seria seguido do mesmo valor máximo de casos que observaríamos caso nenhuma medida fosse tomada. O pico das infecções seria deslocado para o futuro, mas com sua verticalidade preservada - levando invariavelmente ao colapso do sistema de saúde 7 . A relevância dessa projeção em termos de políca sanitária é evidente.

Para modelarmos mais precisamente a disseminação do novo coronavírus, não há que se levar em conta apenas fatores biológicos (o agente infeccioso, o modo de transmissão, período de latência assintomática, a susceptibilidade ou resistência da população...), mas também fatores demográficos, econômicos, sociais, e culturais específicos. Qualquer modelo geral da propagação de COVID-19 no Brasil, ainda que efetivo ao projetar a velocidade de transmissão e o pico de casos, apresentará resultados insatisfatórios quando aplicado a regiões específicas. Pense-se, por exemplo, na projeção do comportamento do vírus em favelas densamente povoadas e com restrito acesso a mecanismos de prevenção. Esse contexto mereceria modelagem específica. Resta claro que $M_{\mathrm{s}}$ será geral, impreciso e idealizado - e estritamente falando, falso. Políticas públicas precisam assim calibrar suas expectativas, e atentar para essas especificidades.

Alguns fatores são também difíceis de serem contemplados e quantificados em tais projeções. Epidemias tendem a desaparecer uma vez que a população adquire certo nível de imunidade. Outras vezes a epidemia é demograficamente contida devido ao paciente morrer muito rapidamente. Frequentemente esses fatores motivam o abandono da busca por uma vacina ou tratamento farmacológico, como no caso da MERS-CoV, que acometeu a Arábia Saudita em 2012. Assim, o desenvolvimento de possíveis vacinas não é, em geral, contemplado por esses modelos. Outros parâmetros são mais fáceis de serem computados. Os mecanismos de transmissão de indivíduo infectado para indivíduo susceptível (descrição microsópica) são bem conhecidos para a maioria das doenças infecciosas, incluindo o novo coronavírus. No caso desse último, o mecanismo principal de transmissão é o contato com

\footnotetext{
${ }^{4} \mathrm{Ib} ., 119$.

5 BASTOS e CAJUEIRO, Modeling and forecasting the early evolution of the Covid-19 pandemic in Brazil.

${ }^{6} \mathrm{O}$ modelo SIR divide a população em três grupos: (S) susceptíveis, mas não infectados; (I) infecciosos e com potencial de transmissão a outros; $(\mathrm{R})$ removidos que estão imunes e não transmitem, ou morreram. Esse é o modelo de referência usado quando se suspeita da impossibilidade de reinfecção. A imunidade dos recuperados de COVID-19 ainda é objeto de controvérsia.

7 Há outros aspectos salientes e merecedores de discusão na análise de Bastos e Cajueiro, como a relação determinística entre os parâmetros S, I e R, e o que aprendemos ao manipulá-los. Mas por questões de brevidade não é possível fazê-lo aqui.
} 
gotículas exaladas por indivíduos contaminados. Sabe-se que a transmissão já ocorre desde o início da infecção mesmo em indivíduos assintomáticos. A dinâmica da transmissão em larga escala (descrição macroscópica) é complexa e requer modelos matemáticos que usem a descrição microscópica para predizer a proliferação social da doença. Modelos epidemiológicos são essenciais, já que experimentos com doenças infecciosas em humanos não são possíveis ou éticos.

Apesar dos modelos epidemiológicos serem idealizados e incompletos, suas predições quantitativas e comparativas acerca da eficácia dos mecanismos de prevenção e controle da propagação de doenças são surpreendentemente robustas ${ }^{8}$, e podem nos indicar qual mecanismo é mais eficaz, norteando assim políticas públicas ${ }^{9}$. Podem ser investigados além dos níveis de vacinação necessários, a ordem de vacinação segundo grupos etários para se conseguir a melhor relação custo-benefício. Pode-se também projetar o impacto de uma mudança comportamental - uso generalizado de máscaras faciais, por exemplo - para a diminuição dos novos casos. Modelos podem ainda ser usados para avaliarmos o grau de sensibilidade das predições a variações de seus parâmetros. Ainda que todos esses usos se mostrassem falhos no caso da pandemia atual, a formulação de modelos tem uma vantagem intrínseca em termos epistêmicos: o de "levar a uma afirmação clara das suposições sobre os mecanismos biológicos e sociológicos que influenciam a propagação da doença. Os parâmetros usados ... devem ter uma interpretação clara, como taxa de contato ou duração da infecção ${ }^{10}$.

Essa busca por clareza nasceu junto com a epidemiologia moderna. Quando modelos epidemiológicos se encontravam em sua infância, ainda na forma de simples diagramas, mapas ou infográficos, as maiores dificuldades encontradas pelos epidemiologistas eram duas. Era preciso convencer o público e as autoridades da utilidade desses instrumentos, e também encontrar os dados com que trabalhar. A iniciativa de recolher dados epidemiológicos ganhou forma com Noah Webster ${ }^{11}$. Em 1795 ele publicou uma circular pedindo que médicos compartilhassem informações sobre a epidemia de febre amarela que assolava partes dos Estados Unidos. $\mathrm{O}$ apelo deu origem a publicações pioneiras no campo da epidemiologia. A motivação nos é dada por Webster: "quando iniciei minhas pesquisas sobre a febre amarela em 1795 eu não possuía nenhum sistema [de crenças] preconcebido para manter. Minha ideia era coletar dados e a partir deles deduzir a verdade" ${ }^{12}$. Webster, leigo em medicina, escreveu uma história das epidemias, e embora tenha falhado em encontrar uma causa para a doença, Webster assertou que "são necessários mais materiais para nos permitir erigir uma teoria das epidemias que merecerá total confiança" 13 . Joshua Kendall observa: "[Webster] estabeleceu um protocolo que os futuros profissionais médicos poderiam seguir, que envolvia reunir o máximo de evidências possível, reunindo os esforços de vários especialistas nas linhas de frente"14.

Na Londres de 1854, afligida pela cólera, a crença difundida era a de que os miasmas seriam os responsáveis pela transmissão da doença. Quando John Snow, um anestesista, se deparou com o problema de tentar explicar um surto de cólera localizado na região do Soho,

\footnotetext{
8 Robustas no sentido de que conclusões semelhantes se seguem a todo um intervalo de valores para parâmetros relevantes, e em mais de um modelo. A robustez de um modelo depende também da frequência com que é testado e ajustado com base em novos dados.

9 Ver HETHCOTE e YORKE, Gonorrhea Transmission Dynamics and Control.

${ }^{10}$ HETHCOTE, Three Basic Epidemiological Models, 122.

${ }^{11}$ Editor do primeiro jornal diário de Nova Iorque, The American Minerva. Lexicógrafo, emprestou seu nome a um famoso dicionário.

${ }^{12}$ WEBSTER, citado por SHAFTEL, The Evolution of American Medical Literature, 102.

${ }^{13}$ WEBSTER, citado por KENDALL, America's Devastating First Plague and the Birth of Epidemiology. ${ }^{14} \mathrm{Ib}$.
} 
ele decidiu mapear os casos de doentes - o que não era estratégia usual. Os mapas mostravam que a maioria dos casos se aglutinava nas proximidades de uma bomba de água pública na Broad Street (hoje Broadwick Street). Snow inferiu ser a água o meio de transmissão da doença, e não a sujeira e odores fétidos da cidade. Notou ele que entre a camada operária da região, a quem em um ponto local se permitia o consumo irrestrito de cerveja, a incidência da doença era menor - o lugar possuia poço de água próprio. Aqui, um rápido emprego dos métodos indutivos de John S. Mill permitiria identificar a origem do surto de Soho ${ }^{15}$.

Muitos não acreditaram inicialmente na teoria de Snow, pois germes não eram então compreendidos, e tampouco os seus mecanismos de transmissão. Mas com a ajuda de seu mapa, ou infográfico, retirou-se a alça da bomba em questão, e o surto, já em declínio, encontrou seu fim. Assim como no caso de Webster, o processo de mapeamento por Snow foi uma tentativa de representar graficamente o que se sabia da demografia da doença na esperança de facilitar alguma inferência útil a sua melhor compreensão. $\mathrm{O}$ mapeamento de Snow não fora guiado por alguma teoria. Tratava-se de um recurso que poderia nos apontar na direção de uma hipótese testável ${ }^{16}$. Lentamente o uso de mapeamentos epidemiológicos, e mais tarde de modelos, ganharia a confiança das autoridades como um instrumento útil para elaboração de políticas sanitárias.

Em nossos tempos atuais o problema parece ser outro. A bem-sucedida relação entre poder preditivo de modelos e políticas públicas acabou por criar no público uma falsa impressão de que modelos são instrumentos capazes de predições verdadeiras. Com exceção de negacionistas, as pessoas em geral acreditam em epidemiologistas e suas projeções, mas acabam por vezes se frustrando quando essas são 'revistas'. A tecno-socióloga Zeynep Tufekci menciona a política de saúde pública britânica em resposta ao COVID-19 como um exemplo disso. Até o início de março deste ano o Reino Unido não havia promovido isolamento social. Fontes não oficiais sugerem que a ideia era deixar o vírus contaminar o público jovem, preservando idosos e grupos de risco, criando-se assim imunidade de rebanho. Essa estratégia temerária foi rapidamente abandonada quando a equipe liderada por Neil Ferguson, do Imperial College London, divulgou uma projeção assustadora. Com base em dados da China e da Itália estimou-se que na ausência de qualquer intervenção mais de meio milhão de britânicos morreria. Esse número ganhou ampla visibilidade midiática, e obrigou o governo de Boris Johnson a instituir medidas de isolamento social.

Para Tufekci os modelos tornam-se por vezes vítimas de seu próprio sucesso, e acabam por parecer, aos olhos do leigo, inadequados ou falsos. Isso ocorre porque modelos descrevem possibilidades sensíveis às nossas ações intervencionistas, que por sua vez acabam por atenuar os danos, suscitando assim dúvidas sobre a real gravidade da doença. Essas dúvidas acabam se tornando instrumento político nas mãos de negacionistas. Após o Reino Unido mudar drasticamente sua política em relação à pandemia, Neil Ferguson passou a estimar cerca de vinte mil mortes. Esse número mais baixo obteve notável repercussão: “um ex-repórter do NY Times a descreveu como 'virada notável' ... o Daily Mail publicou sobre o histórico 'irregular' do cientista ... o The Federalist declarou: 'O cientista cujo modelo pandêmico do juízo final previa o Armageddon recuou das previsões apocalípticas"”'17.

\footnotetext{
15 Ver MILL, System of Logic, Livro III, capítulos 8-10.

${ }^{16}$ A hipótese foi confirmada quando se descobriu que a fonte fora contaminada por uma fossa séptica próxima na qual material contaminado havia sido descartado. Ver ROGERS, John Snow's data journalism: the cholera map that changed the world.

${ }_{17}$ TUFEKCI, Don't Believe the COVID-19 Models.
} 
A linguagem jornalística sugere que os modelos foram revisados, que houve 'recuo' ou 'virada'. Mas a projeção original continha uma série de projeções tomando-se diferentes cenários, desde a não-intervenção à quarentena forçada. Como as epidemias crescem exponencialmente, o grau de sensibilidade das projeções às mudanças nos dados iniciais é alta. Essa sensibilidade é uma característica dos modelos que em geral não é bem compreendida entre o público leigo, que vê na constante 'revisão' das projeções falta de rigor metodológico. Mas trata-se do oposto. E mesmo o ajuste constante dos modelos em face a novos dados é fator indispensável para a performance dos mesmos, e não um vício. Analogamente, também as políticas públicas precisam ser constantemente recalibradas.

\section{Cognição, Entendimento e Explicação}

As frustrações com predições feitas por modelos se originam de desinformação acerca de seus usos e limitações. A relação entre modelos epidemiológicos e políticas sanitárias torna-se bastante visível no contexto de uma pandemia. Mas há outros aspectos salientes que chamam a atenção de filósofos da ciência. Frigg e Hartmann alertam que modelos são veículos para aprendermos sobre o mundo, e que algumas pesquisas científicas são na verdade feitas em modelos de sistemas, e não em sistemas físicos ${ }^{18}$. Espera-se que as descobertas feitas acerca das características do modelo possam ser transferidas para o sistema físico modelado ${ }^{19}$. Essa visão da função cognitiva dos modelos levou a teorias que procuram descrever os processos psicológicos usados ao fazermos inferências lógicas com base na criação e manipulação de modelos, e seus possíveis resultados (model-based reasoning $)^{20}$.

Mary Morgan afirma que há basicamente dois momentos nos quais aprendemos a partir dos modelos: quando os construímos e quando os utilizamos/manipulamos. Ao construirmos um modelo nos envolvemos em "descobrir o que irá se encaixar e funcionar para representar certos aspectos da teoria, do mundo, ou de ambos. A modelagem requer fazermos escolhas, e ali reside o processo de aprendizagem" ${ }^{21}$. Ainda segundo Morgan, o aprendizado propiciado por modelos depende da extensão com que queremos "transferir as coisas que aprendemos ao manipular nossos modelos para nossa teoria ou para o mundo real" 22 .

Mesmo quando o modelo fracassa em representar um sistema real, ao manipular o sistema e suas partes o cientista consegue representar qualitativamente diversos fenômenos empíricos. Morgan ilustra o caso com um modelo econômico proposto por Irving Fisher em 1894, o dos 'reservatórios conectados'. Fisher discute a relação idealizada entre parâmetros econômicos: quantidade de dinheiro $M$, velocidade $V$, volume de negócios $T$ e nível geral de preços $P$, regidos por uma equação geral de trocas $^{23}$. Fisher manipula o modelo inicialmente observando o que precisaria acontecer aos outros parâmetros para que $M$ permanecesse estável. Em um segundo momento Fisher considera as razões pelas quais $M$ deveria oscilar. Essas manipulações acabam por ensinar ao cientista a forma como as leis relevantes operam no mundo do modelo. Tal conhecimento é indubitavelmente instrutivo. Considerações análogas são encontradas nos modelos epidemiológicos, como as relações determinísticas entre os parâmetros SIR.

\footnotetext{
${ }^{18}$ FRIGG e HARTMANN, Models in Science.

19 Ver SWOYER, Structural Representation and Surrogative Reasoning.

${ }^{20}$ Ver MARKOVITS, Model-Based Reasoning, 131.

${ }^{21}$ MORGAN, Learning from models, 386.

${ }^{22} \mathrm{Ib}$.

${ }^{23}$ Ver FISHER, The Mechanics of Bimetallism.
} 
Existe ainda uma difundida tese de que modelos são capazes de explicar fenômenos como a propagação de um vírus ou o equilíbrio de preços. Mas sabemos que esses dois exemplos são idealizações. Podemos dizer que modelos idealizados e suas projeções são verdadeiros? Caso respondamos negativamente, mas queiramos ainda dizer que modelos explicam, temos um problema. Há uma longa tradição oriunda da teoria da explicação por subsunção dedutiva sob leis gerais de Carl Hempel, Paul Oppenheim e Karl Popper, segundo a qual o explanans de uma explicação científica é sempre verdadeiro ${ }^{24}$. Se concordarmos com essa posição, mas quisermos defender que 'falsidades' também explicam, precisamos argumentar que apesar das imprecisões, os modelos podem ser verdadeiros em algum sentido.

Michael Strevens propõe exatamente isso: a representação feita pelo modelo pode ser idealizada e imprecisa sem que com isso seu poder explicativo seja comprometido. Uma abordagem puramente empirista, diz ele, requer apenas que as predições sobre parâmetros observáveis sejam corretas para que possamos dizer que o modelo explica um fenômeno. Desde que o modelo represente de forma verdadeira as relações causais presentes no sistema real modelado - e que se buscam investigar - estamos justificados em dizer que o modelo explica os aspectos relevantes do fenômeno ${ }^{25}$. Há verdade nas causas.

Há que se avaliar também uma abordagem mais pragmática. Talvez seja o caso que modelos expliquem, ainda que falsos, precisamente porque a verdade não é necessária para a provisão de uma explicação. Nancy Cartwright, em sua conhecida definição de explicação científica como simulacro, sustenta que as leis com as quais os físicos se ocupam não governam objetos no mundo real, mas objetos no mundo do modelo. Explicar consiste em "construir um modelo que encaixe o fenômeno na estrutura básica da teoria e, em seguida, derivar análogos para suas leis fenomenológicas" ${ }^{26}$. Dessarte, a explicação que procuramos é o próprio modelo. Cartwright conclui ainda que leis naturais não se encaixam na teoria da subsunção ${ }^{27}$.

Todavia, se pensarmos holisticamente que o entendimento dos fenômenos é o objetivo central da ciência, podemos justificar a centralidade dos modelos na ciência sem termos de nos desculpar por suas imprecisões. Catherine Elgin argumenta que a falsidade dos modelos desempenha um papel importante no nosso entendimento dos fenômenos, refutando a tese de que não há boas razões para aceitarmos falsidades. Elgin afirma que modelos idealizados podem ser instrumentos epistêmicos adequados. A divergência da verdade promoveria o seu funcionamento epistêmico: quando efetivos, os modelos seriam falsidades felizes ${ }^{28}$.

Analogamente à obra de arte, os modelos capturam aspectos relevantes de fenômenos reais sem lhes dever completa fidelidade. A aceitação do modelo como condutor ao conhecimento se deve sobretudo ao endosso recebido pelos membros da comunidade científica. A robustez dos modelos epidemiológicos é fruto do compromisso assumido pela comunidade em representar modelisticamente os aspectos salientes da pandemia. É preciso manter o compromisso epistêmico com os dados disponíveis. São esses dados que permitem a "inferência não trivial, a argumentação e a ação em relação ao tópico ao qual a informação pertence"29. A manutenção desse compromisso inclui a necessária compreensão, ainda que introdutória, de modelos científicos. Cumpre àqueles que se ocupam da divulgação desses

\footnotetext{
24 Ver HEMPEL e OPPENHEIM, Studies in the Logic of Explanation.

${ }^{25}$ Ver STREVENS, Why Explanations Lie: Idealization in Explanation.

${ }^{26}$ CARTWRIGHT, The Simulacrum Account of Explanation, 143.

27 Também conhecido como modelo das leis de cobertura.

${ }^{28}$ Ver ELGIN, True Enough.

${ }^{29} \mathrm{Ib} ., 44$.
} 
instrumentos e suas projeções, a promoção do entendimento de suas sutilezas, usos e limitações. Isso é importante para preservarmos o conhecimento científico de ideologias que procuram desacreditar a aliança entre ciência e políticas públicas.

Vimos que a necessidade de recalibrar os modelos, atualizando suas projeções, é por vezes compreendida erroneamente como imprecisão ou falta de rigor metodológico. Por vezes essa interpretação ganha uma nefasta dimensão política. A epidemia de COVID-19 e a necessidade de isolamento social fez crescer a força daqueles que negam a verdade dos modelos epidemiológicos e suas projeções, e em conseguinte, a necessidade de intervenções. Esses negacionistas exigem o imediato retorno à normalidade, minimizando a gravidade da pandemia. Vivenciamos notavelmente no Brasil e nos Estados Unidos o crescimento de uma militância autoritária empenhada em desacreditar as recomendações da Organização Mundial da Saúde. Essa é talvez uma das razões pelas quais ambos os países foram até o momento os mais duramente atingidos. A OMS chegou a ser rotulada de organismo de esquerda que agiria em interesse próprio, procurando talvez obter benefícios econômicos com a pandemia ${ }^{30}$. Essa reação anticientífica e conspiracionista, que se propaga por meio de tabloides tendenciosos, blogs e redes sociais, explicita uma forma grave de negacionismo, pois ameaça os esforços de preservação de vidas.

O negacionismo certamente não é inédito: negacionistas da evolução, terra planistas, opositores às vacinas, revisionistas históricos, entre outros, circulam há tempos entre nós. O que é inédito no presente é a rápida e profusa dispersão dessas ideias. Keith Kahn-Harris explica que negacionistas reagem ao que consideram um inconveniente: a criação de um consenso moral acerca da coisa certa a fazer ${ }^{31}$. No caso da presente epidemia, rapidamente criou-se um consenso de que preservar vidas por meio do isolamento social é primordial. Negacionistas, alegando agirem em nome da liberdade, atacam os fundamentos científicos que proporcionam esse consenso, no caso as projeções epidemiológicas, dispersando assim ceticismo generalizado para com a ciência. Segundo Kahn-Harris, o negacionismo enquanto movimento é "combativo e extraordinário [pois ao passo que a simples] negação esconde a verdade, o negacionismo constrói uma nova e melhor verdade”. Além disso o negacionismo oferece uma visão distópica do mundo, pregando que não se pode acreditar em autoridades médicas ou instituições: "se você acredita que estão constantemente mentindo para você, paradoxalmente você corre o risco de aceitar as inverdades [dos negacionistas] ... o negacionismo é uma combinação de dúvida e credulidade corrosivas" 32 .

A negação da ciência é talvez o mais saliente sintoma da era da 'pós-verdade', na qual crenças baseadas em evidência científica são suplantadas por crenças amparadas por anedotas, emoções e preconceitos. Crenças dessa natureza podem ser uma ameaça não apenas à ciência, mas ao próprio estado de direito. Negacionistas e militantes da pósverdade são notadamente rumorosos e bem organizados, confrontando valores científicos, como imparcialidade e neutralidade, com fervor ideológico. Todavia, não devemos culpar o leigo por sentir-se confuso: "a profusão de vozes, a pluralidade de opiniões, a cacofonia da controvérsia são suficientes para fazer alguém duvidar do que deveria acreditar"33. Eis o ponto no qual a epistemologia pode ser normativa, elucidando como formar crenças bem justificadas. Cabe aos filósofos da ciência, bem como aos cientistas e profissionais da mídia, restaurar a confiança do leigo - o alvo da desinformação - na confiabilidade dos modelos científicos e suas projeções, bem como no compromisso geral da ciência para com a verdade.

\footnotetext{
${ }^{30}$ Como exemplo local, veja-se EUSTÁQUIO, Etíope, diretor-geral da OMS é líder comunista radical corrupto e garoto propaganda do Covid-19.

${ }^{31}$ KAHN-HARRIS, Denialism: what drives people to reject the truth.

${ }^{32} \mathrm{Ib}$.

$33 \mathrm{Ib}$.
} 
Isso pode ser feito, ao menos em parte, ao demonstrarmos precisamente o que são modelos epidemiológicos, o que podemos esperar deles, e porquê são indispensáveis para a confecção de políticas sanitárias adequadas.

\section{Referências}

BASTOS, S.; CAJUEIRO, D. Modeling and forecasting the early evolution of the Covid-19 pandemic in Brazil. Cornell University: Quantitative Biology (manuscrito enviado em 31 mar. 2020 (pre-print). Disponível em: https://arxiv.org/abs/2003.14288. Acessado em: o8 abr. 2020.

CARTWRIGHT, N. The Simulacrum Account of Explanation. In: How the Laws of Physics Lie. Oxford: Oxford University Press, 1983.

ELGIN, C. True Enough. Cambridge, MA: MIT Press, 2017.

EUSTÁQUIO, O. Etíope, diretor-geral da OMS é líder comunista radical corrupto e garoto propaganda do Covid-19. Agora Paraná, 25 mar. 2020. Disponível em: https://www.agoraparana.com.br/noticia/etiope-diretor-geral-da-oms-e-lider-comunistaradical-corrupto-e-garoto-propaganda-do-covid-19. Acessado em: 19 jun. 2020.

FISHER, I. The Mechanics of Bimetallism. The Economic Journal, v. 4, n. 15, p. 527-537, 1894.

FRIGG, R.; HARTMANN, S. Models in Science. The Stanford Encyclopedia of Philosophy, 2020. Disponível em <https://plato.stanford.edu/archives/spr2020/entries/modelsscience/>. Acesso em: 21 abr. 2020.

HEMPEL, C.; OPPENHEIM, P. Studies in the Logic of Explanation. Philosophy of Science, Chicago, v. 15, n. 2, p. 135-175, 1948.

HETHCOTE, H. Three Basic Epidemiological Models. In: Levin, S. (Org.). Applied Mathematical Ecology. Berlin: Springer, 1989.

HETHCOTE, H.; YORKE, J. Gonorrhea Transmission Dynamics and Control. In: Levin, S. (Org.). Lecture Notes in Biomathematics. Berlin: Springer, 1984.

KAHN-HARRIS, K. Denialism: what drives people to reject the truth. The Guardian, 3 ago. 2018. Disponível em: <https://www.theguardian.com/news/2018/aug/o3/denialism-whatdrives-people-to-reject-the-truth $>$. Acesso em 19 jun. 2020.

KARGON, R.; ACHINSTEIN, P. (Orgs.) Kelvin's Baltimore Lectures and Modern Theoretical Physics. Cambridge, MA: MIT Press, 1987.

KENDALL, J. America's Devastating First Plague and the Birth of Epidemiology. Time, 4 abr. 2020. Disponível em: <https://time.com/5815099/america-first-plague-birthepidemiology/>. Acesso em 18 abr. 2020.

MARKOVITS, H. Model-Based Reasoning. In: Seel N. (Org.) Encyclopedia of the Sciences of Learning. Boston, MA: Springer, 2012.

MILL, J. S. A System of Logic, Ratiocinative and Inductive: Being a Connected View of the Principles of Evidence, and the Methods of Scientific Investigation. Cambridge: Cambridge University Press, 2011 [1843].

MORGAN, M. Learning from Models. In: Morgan, M.; Morrison, M. (Orgs.). Models as Mediators: Perspectives on Natural and Social Science. Cambridge: Cambridge University Press. 
10 | Modelos científicos em tempos de pandemia

ROGERS, S. John Snow's data journalism: the cholera map that changed the world. The Guardian, 15 mar. 2020. Disponível em: <https://www.theguardian.com/news/datablog/2013/mar/15/john-snow-cholera-map $>$. Acesso em: 19 abr. 2020.

SHAFTEL, N. The Evolution of American Medical Literature. In: Martí-Ibáñez, F. History of American Medicine: A Symposium. New York: MD Publications, 1959.

STREVENS, M. Why Explanations Lie: Idealization in Explanation. In: Depth: An Account of Scientific Explanation. Boston: Harvard University Press, 2008.

SWOYER, C. Structural Representation and Surrogative Reasoning. Synthese, v. 87, n. 3, p. 449-508, 1991.

TUFEKCI, Z. Don't Believe the COVID-19 Models. The Atlantic, 02 abr. 2020. Disponível em: $<$ https://www.theatlantic.com/technology/archive/2020/04/coronavirus-models-arentsupposed-be-right/609271/>. Acesso em: 19 abr. 2020. 